Available online on 15.9.2019 at http://ujpr.org
Universal Journal of Pharmaceutical Research
An International Peer Reviewed Journal
Open access to Pharmaceutical research
This is an open access article distributed under the terms of the Creative Commons Attribution-Non
Commercial Share Alike 4.0 License which permits unrestricted non commercial use,
provided the original work is properly cited
Volume 4, Issue 4, 2019

\title{
FORMULATION AND EVALUATION OF COLON TARGETED MATRIX TABLETS CONTAINING EXTRACT OF SOLENOSTEMMA ARGEL (HARGEL)

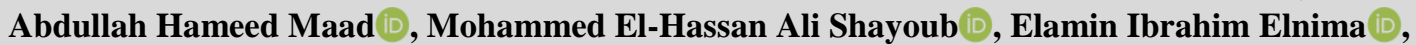 Zuheir Osman $1 D$, Fatehalrahman F. Magbool $1 D *$ Department of Pharmaceutics, Khartoum University, P.O. Box 1996, Sudan.
}

\section{ABSTRACT}

Objective: The objective of the present study is to formulate colon targeted matrix tablets containing Solenostemma argel extract using guar gum alone or in combination with either HPMC K15M, with Eudragit S100, or with both them.

Methods: The Hargel colon targeted matrix tablets were prepared by wet granulation method. The prepared matrix tablets were evaluated for the weight variation, hardness, friability, and in-vitro drug release study in three different media. The formulations showed compliance with pharmacopoeial standards except that containing guar gum alone.

Results: There was no interaction between drug, polymer and other excipients. It was confirmed by FTIR studies. Among the formulations, GHE2 (i.e. containing triple polymer mixture) showed good results in release retardation and other physicochemical properties of matrix tablets when compare to other formulations.

Conclusion: The optimum formulation (GHE2) was stable when it was stored at $45^{\circ} / 75 \%$ RH for 3 months. The formulation GHE2 was considered the most suitable formula for targeted the colon.

Keywords: Colon targeted matrix tablets, Eudragit S100, guar gum, HPMC K15M, Hargel extract.

Article Info: Received 3 July 2019; Revised 9 August; Accepted 3 September, Available online 15 September 2019

口isita Cite this article-

Maad AH, Shayoub MEA, Elnima EI, Osman Z, Magbool FF. Formulation and evaluation of colon targeted matrix tablets containing extract of Solenostemma Argel (Hargel). Universal Journal of Pharmaceutical Research 2019; 4(4): 33-38.

DOI: https://doi.org/10.22270/ujpr.v4i4.297

Address for Correspondence:

Fatehalrahman F. Magbool, Department of Pharmaceutics, Khartoum University, P.O. Box 1998, Sudan. E-mail: fmagbool@yahoo.com

\section{INTRODUCTION}

Colon delivery systems are potential for delivering various drugs to treat the local diseases for colon including colon cancer ${ }^{1}$. Guar gum is reported to be potential carrier for colon specific drug delivery, due to its drug release retarding property and susceptibility to microbial degradation in the large intestine ${ }^{2-4}$. It is the best polymer for control release matrix tablets but it produces burst effect for water-soluble drugs in starting hrs. In order to minimize it a combination of guar gum with other polymers such as HPMC K15M or/and Eudragit S100 is necessary. Indeed, a combination of these polymers is an approach that may allow formulators to develop colon targeting dosage form that may exhibits performance improvements over the individual polymer components. It provides a neat and smooth means of combining desirable properties of different polymers ${ }^{6,5}$. Recently, a lot of studies reported that a combination of different gums or polymers to increase matrix viscosity and optimize release often leads to synergistic interactions ${ }^{7,8}$. To achieve colon delivery, preparation of matrix tablets is simple method when compared to other methods like tablets coated with different polymers and chemical conjugation of drug $^{9}$. Colorectal cancer is one of the highest incidence and mortality cancers worldwide ${ }^{10}$. In Sudan, colorectal cancer is the fifth most commonly diagnosed cancer ${ }^{11}$. The serious side effects of chemotherapeutics and the resistance developed by tumor cells in addition to recurrence and metastasis high lightened the urge need for search to find more safe and efficient therapies ${ }^{12,13}$. Plant derived products have been valuable source for the discovery and development of unique anticancer drugs, which target multiple pathways in cancer cells and are associated with limited or no side effects ${ }^{14,15}$. Solenostemma argel is one of the most commonly used medicinal plants in Sudan. Many of scientific studies have been carried out reporting that the extracts of Solenostemma argel possess various antitumor activities $^{16-19}$.The main objective of this study is to formulate, and evaluate a novel matrix tablet using the methanol extract of Solenostemma argel (Hargel) leaves to target a colon, for provide effective, and safe therapy for colorectal cancer. 


\section{MATERIALS AND METHODS}

Hargel dried leaves were obtained from local market in Khartoum. Guar gum was procured from (Gitaf, Sudan). HPMC K15M was obtained from (Dow Chemical, Michigan, USA). Eudragit S100 was received from (Evonik, Germany). Lactose monohydrate was obtained from (Breckland scientific supplier, UK). MCC PH 101 and Talc were obtained from (A Johnson Matthy, UK).PVP K30and Magnesium stearate were obtained from (Techno pharmchem, India). All other chemicals used were of analytical grade.

Preparation of Solenostemma argel (Hargel) extract Hargel dried leaves were cleaned from other parts of the plant and crushed by hand, then $1 \mathrm{Kg}$ of hargel dried leaves exhaustively extracted with $80 \%$ methanol in Soxhlet apparatus. The solvent was evaporated under reduced pressure using Rotary evaporator. The extract was maintained at $4^{0} \mathrm{C}$ and protect from light ${ }^{20}$. The methanolic extract of Solenostemma argel leaves was formulated as colon targeted matrix tablet by wet granulation method using different polymers include Guar gum, HPMC K15M, and Eudragit S100 in addition to other excipients such as MCC as filler, PVP $\mathrm{K} 30$ as binder, $\mathrm{Mg}$ stearate as lubricant, and Talc as glidant.

Compatibility study of Hargel extract and polymers The infrared spectra of drug alone (Hargel extract), and granules of Hargel matrix tablet (G2, GH2, GE2, and GHE2) were recorded in range from 400 to $4000 \mathrm{~cm}^{-1}$ on FTIR to detect the drug-polymers interactions. The IR spectra for the test samples were obtained using $\mathrm{KBr}$ disk method using an FTIR spectrometer. The resultant spectra were compared for any possible changes in the peaks of the spectra ${ }^{21}$.

Preparation of Hargel colon targeted matrix tablets Weighed quantity of Hargel extract, Guar gum, HPMC K15M, Eudragit S100, and MCC were sieved and mixed properly in polybag for 15 minutes. A binder solution (PVP K30 in mixture of Isopropyl alcohol and water solution 3:1) was added to above blend to prepare a dough mass. The dough mass was granulated using a 14 mesh screen and the granules obtained were dried in oven at $80^{\circ} \mathrm{C}$ for $2 \mathrm{hrs}$. The dried granules were passed through 20 \# sieve. The dried granules were lubricated using talc and magnesium Stearate $(2: 1)$ for 5 minutes. The lubricated granules were compressed to tablets using a $12 \mathrm{~mm}$ concave single punch tablet machine (Korsch, Germany). Table 1 shows the compositions of Hargel colon targeted matrix tablet of 12 Formulae.

\section{Evaluation of Granules}

\section{Angle of repose}

The angle of repose was calculated using the following equation:

Where,

$$
\tan \theta=\frac{\mathrm{h}}{\mathrm{r}}
$$

$\theta$ - angle of repose

$\mathrm{r}$ - Radius of base of the heap $(\mathrm{cm})$ and

$\mathrm{h}$ - Height of the heap $(\mathrm{cm})$.

Bulk and Tapped density
To calculate the densities the following equations were used:

$$
\begin{gathered}
\text { Bulk density }=\frac{\text { Weight of the powder }}{\text { bulk Volume }} \\
\text { Tapped density }=\frac{\text { Weight of the powder }}{\text { Tapped Volume }}
\end{gathered}
$$

Compressibility index

Carr's index was calculated according to equation given below:

$$
\text { Carr's index }=\frac{\text { Tapped density }- \text { Bulk density }}{\text { Tapped density }}
$$

\section{Hausner's ratio}

It is the ratio of tapped density to bulk density of the powder and measured by employing the following formula.

$$
\begin{aligned}
& \text { Hausner's ratio }=\frac{\text { Tapped density }}{\text { Bulk density }} \\
& \text { Evaluation of Hargel Colon Targeted Matrix } \\
& \text { Tablets } \\
& \text { Weight variation test }
\end{aligned}
$$

The weight variation test was analyzed by selecting twenty tablets randomly and average weights were determined. Then individual tablet weighed and compared with the average. The requirement met the (USP, 2016) ${ }^{22}$; if not more than two tablets differ from the average weight $\pm 5 \%$ and no tablet differs in weight by double that percentage, the tablets will be accepted.

\section{Hardness test}

The resistance of tablets to shipping or breakage under conditions of storage, transportation, and handling before usage depends on its hardness. The hardness of tablet of each formulation was measured by Monsanto hardness tester. The hardness was measured in terms of $\mathrm{kg} / \mathrm{cm}^{2}$. The test was conducted as per (USP, 2016) ${ }^{22}$.

\section{Friability test}

Friability is the measure of tablet strength. Erweka Friabilitor was used to perform the test. Twenty tablets were weighed accurately and placed in the tumbling apparatus that revolves at $25 \mathrm{rpm}$ dropping the tablets through a distance of six inches with each revolution. After 4 min., the tablets were weighed and the percentage loss in tablet weight was determined. Conventional compressed tablets that lose less than 0.5 to $1.0 \%$ of their weight are generally considered acceptable. The test was conducted as per (USP, 2016) ${ }^{22}$.

\section{Thickness test}

Thickness was calculated using Vernier calipers. Ten tablets from each formula were used, and average values were calculated. The test was conducted as per (USP, 2016) ${ }^{22}$.

\section{In-vitro drug release study}

The drug release studies were carried out using USP dissolution test apparatus I (basket) at $50 \mathrm{rpm}$ and $37 \pm 0.5^{\circ} \mathrm{C}$ temperature using $500 \mathrm{ml}$ of $0.1 \mathrm{~N} \mathrm{HCl} \mathrm{pH}$ 1.2 (simulated gastric fluid) a dissolution medium in the first $2 \mathrm{~h}$ of study as the average gastric emptying time is about $2 \mathrm{~h}$. At the end of $2 \mathrm{~h}$, the dissolution media was replaced with $500 \mathrm{ml}$ of phosphate buffer pH 6.8 (simulated intestinal fluid) and drug release 
study was continued for another $3 \mathrm{~h}$ as the average small intestine transit time is about $3 \mathrm{~h}$ (i.e., total $5 \mathrm{~h}$ ). At the end of $5 \mathrm{~h}$, the dissolution media was replaced with $500 \mathrm{ml}$ of phosphate buffer $\mathrm{pH} 7.4$ (simulated colonic fluid) and drug release study was continued for next 19 h. $10 \mathrm{ml}$ samples were withdrawn at regular time intervals and correspondingly replaced with fresh media. The amount of drug release was analyzed spectrophotometrically at $\lambda_{\max }$ of $265 \mathrm{~nm}^{23}$. Stability Study

The best formulation was subjected to accelerated stability study according to ICH guidelines at temperature $45 \pm 20 \mathrm{C}$ and $75 \pm 5 \% \mathrm{RH}$ (Relative Humidity) for 3 months in stability chamber. At the end of each month, the physicochemical properties of tablets including organoleptic properties, average weight, hardness, friability, and dissolution were evaluated.

\section{Statistical Analysis}

The results obtained are expressed as a mean \pm standard deviation calculated using Microsoft excel 2010 software. Statistical analysis was performed using SPSS version 20.0 for windows (SPSS Inc. Sep 2011).

Table 1: The Compositions of colon targeted matrix tablet.

\begin{tabular}{lcccccccccccc}
\hline Ingredients & G1 & G2 & G3 & G4 & GH1 & GH2 & GH3 & GE1 & GE2 & GE3 & GHE1 & GHE2 \\
\hline Hargel Extract (mg) & 90 & 90 & 90 & 90 & 90 & 90 & 90 & 90 & 90 & 90 & 90 & 90 \\
Guar gum (mg) & 90 & 180 & 180 & 180 & 90 & 180 & 90 & 90 & 180 & 90 & 90 & 180 \\
HPMC K15M (mg) & - & - & - & - & 90 & 90 & 180 & - & - & - & 90 & 90 \\
Eudragit S100 (mg) & - & - & - & - & - & - & - & 90 & 90 & 180 & 90 & 90 \\
Lactose (mg) & - & - & - & 70 & - & - & - & - & - & - & - & - \\
MCC (mg) & 30 & 30 & 100 & 30 & 30 & 30 & 30 & 30 & 30 & 30 & 30 & 30 \\
PVP (mg) & 18 & 18 & 18 & 18 & 18 & 18 & 18 & 18 & 18 & 18 & 18 & 18 \\
Talc (mg) & 8 & 8 & 8 & 8 & 8 & 8 & 8 & 8 & 8 & 8 & 8 & 8 \\
Mg. Stearate (mg) & 4 & 4 & 4 & 4 & 4 & 4 & 4 & 4 & 4 & 4 & 4 & 4 \\
\hline
\end{tabular}

G: Guar gum, GH: Guar gum + HPMC K15M, GE: Guar gum + Eudragit S100,

GHE: Guar gum + HPMC K15M + Eudragit S100

RESULTS AND DISCUSSION

Compatibility Study of Hargel Extract and Polymers

Figure 1 and Figure 2 display the IR spectra of physical mixture of hargel extract and guar gum (G2), physical mixture of hargel extract, guar gum and HPMC K15M (GH2), physical mixture of hargel extract, guar gum and Eudragit S100 (GE2), and physical mixture of hargel extract, guar gum, HPMC K15M and Eudragit S100 (GHE2).From these Infrared spectra, it observes that hargel extract showed characteristic peaks at $3417.63 \mathrm{~cm}^{-1}$ (O-H bending), $2904.60 \mathrm{~cm}^{-1}$ (C-H stretching), $1737.74 \mathrm{~cm}^{-1}$ ( $\mathrm{C}=\mathrm{O}$ bending), and 1290.29 $\mathrm{cm}^{-1}$ (C-N bending). Furthermore, there is not significant change between these peaks and peaks obtained in the spectra of each physical mixture of hargel extract with polymers used. Therefore, the hargel extract is compatible with all polymers used.

\section{Evaluation of Granules}

Table 2 shows the results of Angle of repose, Bulk density, Tapped density, Carr's index, and Hausner's ratio for granules of all formulae. The results of granules evaluation summarized in (Table 2) indicate good flow properties of prepared granules for all formulae. This is observed from the obtained results of angle of repose $\left(25.15^{-} 32.83^{\circ} \mathrm{C}\right)$ which indicate good flow properties of prepared granules. According to table 2 , the compressibility index values up to $20 \%$ and Hausner's ratio less than 1.25 indicate fair to good compressibility and flowability.

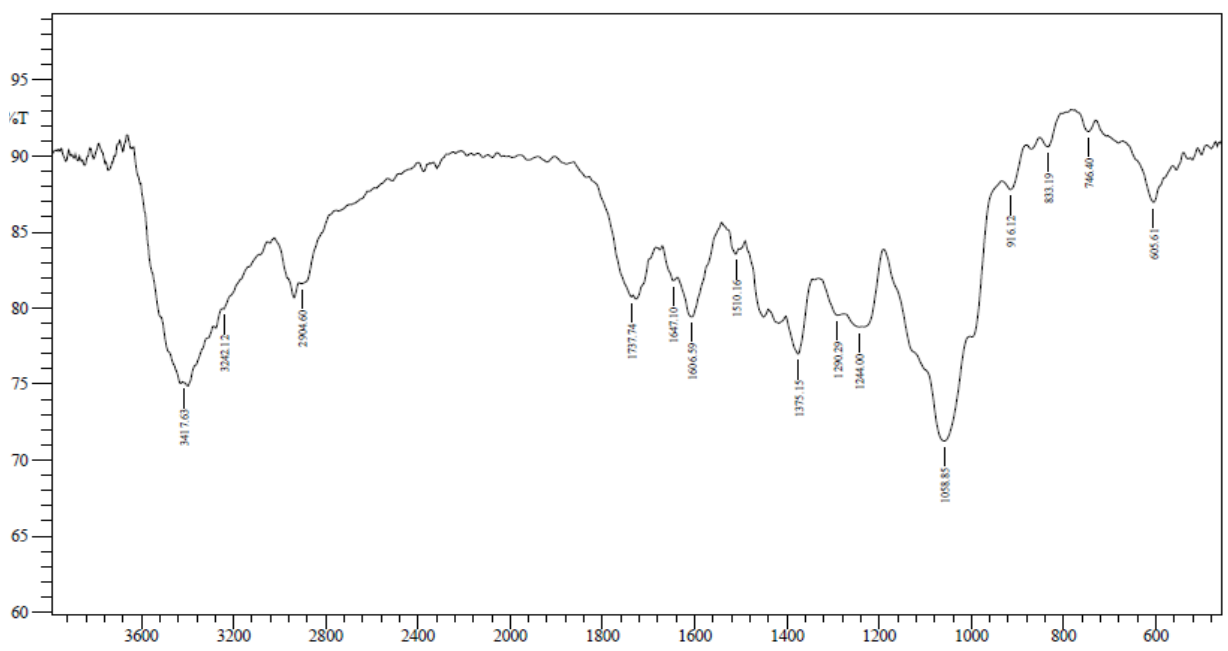

Figure 1: FT-IR spectrum of the methanolic extract of Solenostemma argel leaves. 


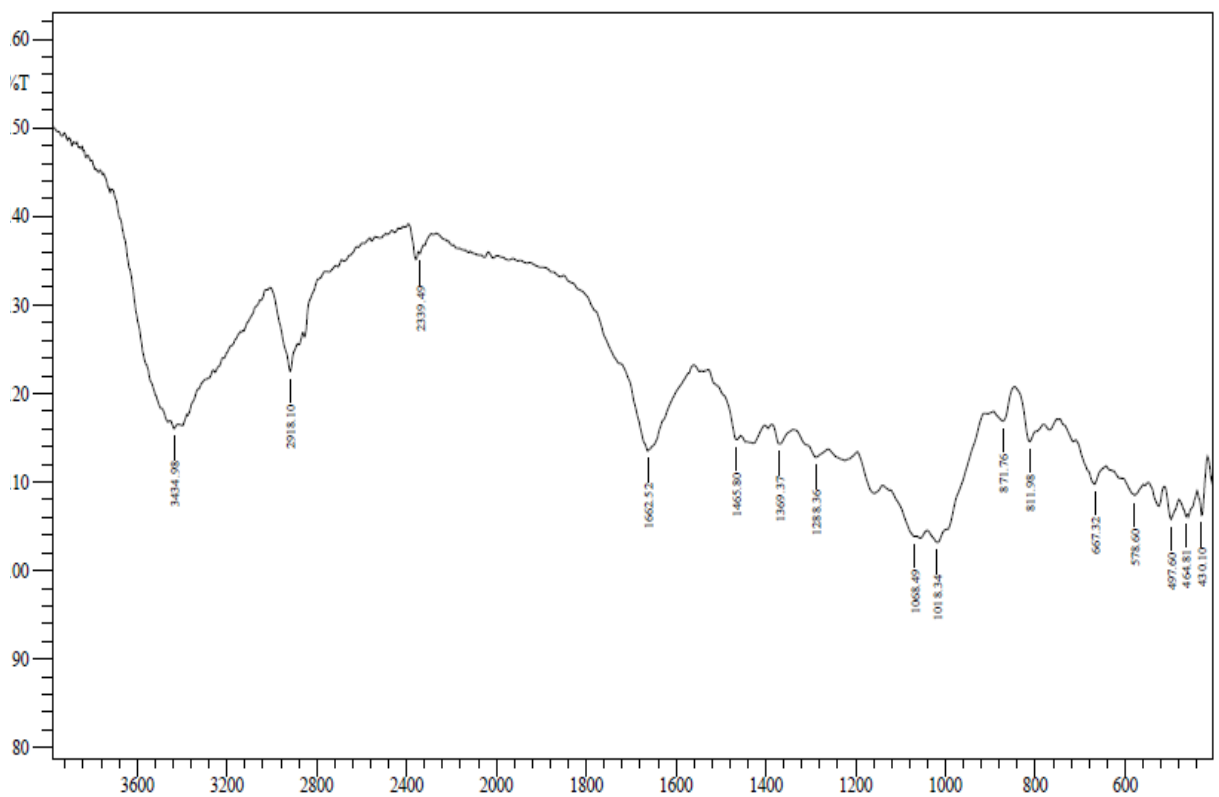

Figure 2: The compatibility between hargel leaf methanolic extract and guar gum, Eudragit and HPMC.

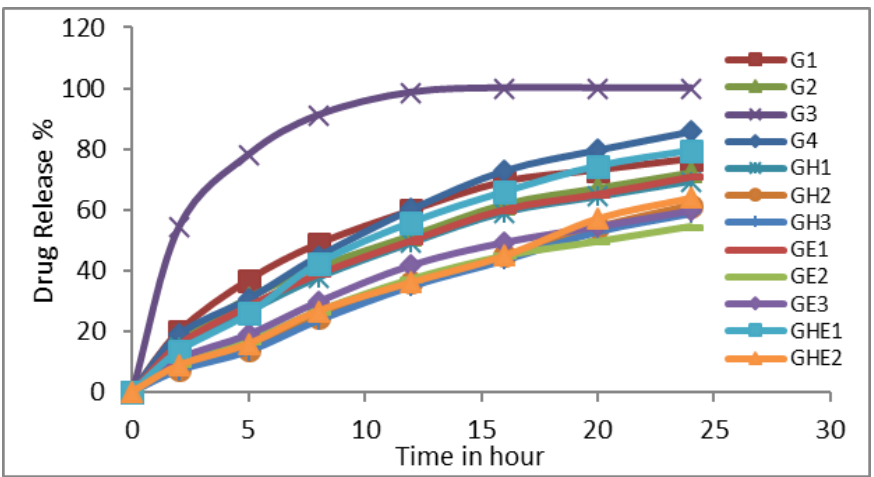

Figure 3: In vitro drug release profile of hargel colon targeted matrix tablets of all formulae.

Table 2: Evaluation of granules of all formulations.

\begin{tabular}{lccccc}
\hline $\begin{array}{l}\text { Formulation } \\
\text { code }\end{array}$ & $\begin{array}{c}\text { Angle of } \\
\text { repose }\end{array}$ & Bulk density & Tapped density & $\begin{array}{c}\text { Carr's } \\
\text { index }\end{array}$ & $\begin{array}{c}\text { Hausner's } \\
\text { ratio }\end{array}$ \\
\hline G1 & $33.24 \pm 0.75$ & $0.3774 \pm 0.0071$ & $0.4653 \pm 0.0108$ & $18.87 \pm 0.36$ & $1.23 \pm 0.01$ \\
G2 & $32.83 \pm 0.94$ & $0.3394 \pm 0.0149$ & $0.4112 \pm 0.0130$ & $17.47 \pm 1.92$ & $1.21 \pm 0.03$ \\
G3 & $31.67 \pm 0.76$ & $0.3509 \pm 0.0062$ & $0.4204 \pm 0.0225$ & $16.41 \pm 2.97$ & $1.20 \pm 0.04$ \\
G4 & $33.24 \pm 0.75$ & $0.3871 \pm 0.0044$ & $0.4695 \pm 0.0224$ & $17.43 \pm 3.44$ & $1.21 \pm 0.05$ \\
GH1 & $29.27 \pm 1.10$ & $0.3681 \pm 0.0039$ & $0.4584 \pm 0.0162$ & $19.63 \pm 2.80$ & $1.23 \pm 0.03$ \\
GH2 & $27.89 \pm 0.40$ & $0.4317 \pm 0.0053$ & $0.5088 \pm 0.0152$ & $15.11 \pm 2.18$ & $1.18 \pm 0.03$ \\
GH3 & $27.67 \pm 1.26$ & $0.3826 \pm 0.0155$ & $0.4584 \pm 0.0162$ & $16.55 \pm 0.50$ & $1.20 \pm 0.01$ \\
GE1 & $27.11 \pm 0.47$ & $0.3297 \pm 0.0062$ & $0.3871 \pm 0.0044$ & $14.82 \pm 1.41$ & $1.17 \pm 0.02$ \\
GE2 & $28.53 \pm 0.06$ & $0.3824 \pm 0.0111$ & $0.4446 \pm 0.0099$ & $14.00 \pm 0.72$ & $1.16 \pm 0.01$ \\
GE3 & $27.17 \pm 1.04$ & $0.3593 \pm 0.0037$ & $0.4138 \pm 0.0049$ & $13.17 \pm 0.97$ & $1.15 \pm 0.01$ \\
GHE1 & $25.15 \pm 0.24$ & $0.3410 \pm 0.0066$ & $0.3923 \pm 0.0077$ & $13.07 \pm 0.89$ & $1.15 \pm 0.01$ \\
GHE2 & $27.37 \pm 2.14$ & $0.3243 \pm 0.0031$ & $0.3705 \pm 0.0069$ & $12.44 \pm 1.00$ & 1.140 .01 \\
\hline
\end{tabular}

G: Guar gum, GH: Guar gum + HPMC K15M, GE: Guar gum + Eudragit S100, GHE: Guar gum + HPMC K15M + Eudragit S100

Evaluation of Hargel Colon Targeted Matrix Tablets

The colon targeted matrix tablets were prepared using guar gum alone, and in combination either with HPMC K15M, with Eudragit S100, or with both HPMC K15M and Eudragit S100. Thus, twelve formulations were prepared (Table 1). Table 3 shows the results of weight variation test, hardness test, friability test, and thickness test for prepared hargel colon targeted matrix tablets of all formulae. The results indicate that the weight variation for different formulations is found to be within the pharmacopeia limit of $5 \%$ as per USP standard. Also, the thickness is uniform and reproducible. The results of hardness test demonstrated that matrices of guar gum alone (G1-G4) failed in the test, this is attributed to the compaction properties of guar gum ${ }^{24}$. 
Table 3: Evaluation of prepared hargel colon targeted matrix tablets of all formulae.

\begin{tabular}{|c|c|c|c|c|c|}
\hline \multirow[t]{2}{*}{$\begin{array}{l}\text { Formulation } \\
\text { Code }\end{array}$} & \multicolumn{2}{|c|}{$\begin{array}{c}\text { Weight variation (mg) } \\
(\mathbf{n = 2 0})\end{array}$} & \multirow[t]{2}{*}{$\begin{array}{c}\text { Hardness } \\
\left(\mathrm{kg} / \mathrm{cm}^{2}\right) \\
(\mathrm{n}=10)\end{array}$} & \multirow[t]{2}{*}{$\begin{array}{c}\text { Friability } \\
(\%) \\
(\mathbf{n}=10)\end{array}$} & \multirow[t]{2}{*}{$\begin{array}{c}\text { Thickness } \\
\text { (mm) } \\
(\mathbf{n = 1 0})\end{array}$} \\
\hline & $\begin{array}{l}\text { Weight } \\
\text { Variation }\end{array}$ & $\begin{array}{c}\text { Deviation } \\
(\%)\end{array}$ & & & \\
\hline G1 & $242.3 \pm 3.8$ & $1.5 \pm 1.4$ & $1.18 \pm 0.06$ & $93.5 \pm 2.85$ & $1.82 \pm 0.01$ \\
\hline G2 & $332.0 \pm 0.7$ & $1.1 \pm 1.0$ & $1.53 \pm 0.12$ & $87.2 \pm 3.01$ & $2.53 \pm 0.03$ \\
\hline G3 & $402.5 \pm 0.9$ & $1.1 \pm 0.9$ & $3.92 \pm 0.28$ & $1.2 \pm 0.1$ & $2.84 \pm 0.01$ \\
\hline G4 & $401.5 \pm 1.1$ & $1.0 \pm 0.8$ & $3.43 \pm 0.09$ & $1.4 \pm 0.1$ & $2.96 \pm 0.01$ \\
\hline GH1 & $332.8 \pm 1.0$ & $1.4 \pm 1.0$ & $3.23 \pm 0.06$ & $1.4 \pm 0.1$ & $2.48 \pm 0.00$ \\
\hline $\mathrm{GH} 2$ & $420.2 \pm 0.9$ & $0.9 \pm 1.1$ & $3.24 \pm 0.10$ & $1.3 \pm 0.2$ & $3.25 \pm 0.01$ \\
\hline GH3 & $418.5 \pm 0.8$ & $1.0 \pm 0.9$ & $4.50 \pm 0.07$ & $0.8 \pm 0.1$ & $3.18 \pm 0.01$ \\
\hline GE1 & $331.9 \pm 1.1$ & $1.0 \pm 0.8$ & $3.70 \pm 0.07$ & $1.0 \pm 0.1$ & $2.47 \pm 0.01$ \\
\hline GE2 & $419.5 \pm 0.7$ & $0.6 \pm 0.7$ & $4.25 \pm 0.17$ & $0.8 \pm 0.1$ & $3.12 \pm 0.01$ \\
\hline GE3 & $419.3 \pm 0.5$ & $0.9 \pm 0.9$ & $5.58 \pm 0.09$ & $0.7 \pm 0.1$ & $3.18 \pm 0.00$ \\
\hline GHE1 & $420.5 \pm 0.8$ & $0.8 \pm 0.9$ & $5.11 \pm 0.06$ & $0.4 \pm 0.1$ & $3.18 \pm 0.01$ \\
\hline GHE2 & $511.4 \pm 0.7$ & $0.6 \pm 0.6$ & $5.64 \pm 0.12$ & $0.3 \pm 0.1$ & 3.800 .01 \\
\hline
\end{tabular}

G: Guar gum, GH: Guar gum + HPMC K15M, GE: Guar gum + Eudragit S100,GHE: Guar gum + HPMC K15M + Eudragit S100

Table 4: The accelerated stability study test for the formula (GHE2).

\begin{tabular}{llccc}
\hline Test time & Color & $\begin{array}{c}\text { Average weight } \\
(\mathbf{m g})\end{array}$ & $\begin{array}{c}\text { Hardness } \\
\left(\mathbf{k g} / \mathbf{c m}^{\mathbf{2}}\right)\end{array}$ & $\begin{array}{c}\text { Friability } \\
(\mathbf{\%})\end{array}$ \\
\hline Zero Time & Pale green & $511.4 \pm 0.7$ & $5.64 \pm 0.12$ & $0.3 \pm 0.1$ \\
1 month & Pale green & $510 \pm 0.7$ & $5.53 \pm 0.05$ & $0.3 \pm 0.1$ \\
2 months & Pale green & $510.3 \pm 1.0$ & $5.68 \pm 0.18$ & $0.2 \pm 0.1$ \\
3 months & Pale green & $509.6 \pm 0.3$ & $5.72 \pm 0.12$ & $0.3 \pm 0.0$ \\
\hline
\end{tabular}

However, the hardness is a parameter which can be related directly to the compression force used that causes decreasing in the powder volume due to elastic and/or plastic deformation and the degree of particle attrition behaviors of the particle-particle bonds in the powder mass ${ }^{25}$. The hardness of the matrices containing a combination of guar gum either with HPMC K15M, with Eudragit S100, or with both them was found to be satisfactory and conformed to those given in pharmacopeia (USP, 2016). This indicates that incorporation of both HPMC K15M and Eudragit S100 to guar gum provides more mechanical strength for matrix tablets and, hence, resulted in successfully preparation of matrix tablets with a required hardness. The results of friability test revealed that matrices containing guar gum only (G1 - G4) failed in the test, this is due to their hardness which is extremely low. However, the friability was affected by the content of guar gum where it showed higher with the large quantity of guar gum ${ }^{26}$.The friability of the matrices containing a combination of guar gum either with HPMC K15M, with Eudragit S100, or with both them was found to be reasonable and conformed to those given in pharmacopeia (USP, 2016).

\section{In-vitro drug release study}

The dissolution test was carried out for the twelve formulae using three different dissolution medium $(0.1 \mathrm{~N} \mathrm{HCl} \mathrm{pH} \mathrm{1.2,} \mathrm{phosphate} \mathrm{buffer} \mathrm{pH} 6.8$ and $\mathrm{pH}$ 7.4). The following results were obtained after carrying the dissolution test for 24 hours, by measuring drug release from matrix tablets at different time intervals $(2,5,8,12,16,20$, and 24 hour). The results of the dissolution test for 12 formulae are shown in
(Figure 6). The results demonstrated that the matrix tablets retained their physical integrity up to $24 \mathrm{~h}$ of the dissolution study conducted without rat caecal content in the dissolution medium except that containing guar gum alone which are divided into two parts. Matrix tablets containing guar gum alone showed higher percent release compared to others which are containing polymer combinations. According to Figure 6 , the percent of drug released from matrix tablets containing guar gum alone was ranged between 30 $35.74 \%$ after $5 \mathrm{~h}$, while it was ranged from $13.9-28.2 \%$ for matrix tablets containing the polymer combinations. However, the drug release rate from matrix tablets is dependent on the formation and viscosity of gel layer and its swelling or erosion rate ${ }^{27}$. This result suggests that guar gum alone was unable to retard the drug release in the stomach and small intestine, while the matrices containing a polymer combinations could be retarded the drug release in stomach and small intestine and, hence, capable to deliver the drug (Hargel extract) to a colon.

\section{Stability study}

The results of accelerated stability study test for the best formula (GHE2) revealed that the matrix tablets retained their organoleptic and physicochemical characteristics, over three months of storage. Therefore, it could be considered stable according to the ICH guidelines.

\section{CONCLUSION}

The effective extract of $S$. argel can be successfully formulated as colon targeted matrix tablet by wet granulation method. The results suggest that matrix tablet containing a combination of guar gum with 
HPMC K15M and Eudragit S100 (GHE2) was most likely to provide targeting of drug (Hargel extract) for treatment colorectal cancer.

\section{ACKNOWLEDGEMENT}

The authors are thankful to wish to Gitaf Company and Azal Industries, Khartoum, Sudan, for providing the gift sample of Guar gum, HPMC K15M and Eudragit S100.

\section{AUTHOR'S CONTRIBUTION}

All authors have worked equally for this work.

\section{CONFLICT OF INTEREST}

No conflict of interest associated with this work.

\section{REFERENCES}

1. Patel MM, Shah T, Amin A. Therapeutic opportunities in colon-specific drug-delivery systems. Critical Rev Therap Drug Car Sys 2007; 24(2).

https://doi.org/10.1615/critrevtherdrugcarriersyst.v24.i2.20

2. Aswar P. et al. Development and in-vitro evaluation of colon-specific formulations for orally administered diclofenac sodium. Arch Pharm Sci Res 2009; 1: 48-53.

3. Tomlin J, Taylor J, Read N. The effects of mixed fecal bacteria on a selection of viscous polysaccharides in vitro. Nutrition Reports Int 1989; 39(1):121-135. https://doi.org/10.1079/BJN19900058

4. Hartemink R, Schoustra SE, Rombouts FM, Degradation of guar gum by intestinal bacteria. Bioscience and microflora 1999; 18(1): 17-25.

5. Domb AJ. Biodegradable polymers derived from amino acids. Biomaterials 1990; 11(9): 686-689. https://doi.org/10.1002/mabi.201100324

6. Ilium L. Chitosan and its use as a pharmaceutical excipient. Pharmaceutical research 1998; 15(9): 1326-1331. https://doi.org/10.1023/A:1011929016601

7. Sujja-Areevath J, et al. Relationship between swelling, erosion and drug release in hydrophillic natural gum minimatrix formulations. Europ J Pharm Sci 1998: 6(3):207-217. https://doi.org/10.1016/S0928-0987(97)00072-9

8. Munday DL, Cox PJ. Compressed xanthan and karaya gum matrices: hydration, erosion and drug release mechanisms. Int J Pharmaceutics 2000; 203(1-2):179-192. https://doi.org/10.1016/S0378-5173(00)00444-0

9. Patel H, et al. Matrix type drug delivery system: A review. J Pharm Sci Res Biosc Res 2011; 1(3): 143-151.

10. Ferlay $\mathrm{J}$, et al. Cancer incidence and mortality worldwide: sources, methods and major patterns in GLOBOCAN 2012. Int J Can 2015; 136(5): E359-E386. https://doi.org/10.1002/ijc.29210

11. Saeed IE, et al. Cancer incidence in Khartoum, Sudan: first results from the Cancer Registry, 2009-2010. Cancer medicine 2014; 3(4): 1075-1084 https://doi.org/10.1002/cam4.254

12. Díaz R, et al. Clinical predictors of severe toxicity in patients treated with combination chemotherapy with irinotecan and/or oxaliplatin for metastatic colorectal cancer. Med Oncol 2006; 23(3): 347-357. https://doi.org/10.1385/MO:23:3:347

13. Shekhar PV. Drug resistance: challenges to effective therapy. Curr Cancer Drug Targets 2011; 11(5): 613-623. https://doi.org/10.2174/156800911795655921

14. Cragg GM, Newman DJ. Plants as a source of anti-cancer agents. J Ethnopharmacol 2005; 100(1-2): 72-79.

15. Ramasamy K, Agarwal R. Multitargeted therapy of cancer by silymarin. Cancer lett 2008; 269(2): 352-362. https://doi.org/10.1016/j.canlet.2008.03.053

16. Nassr-Allah AA et al. Anti-cancer and anti-oxidant activity of some Egyptian medicinal plants. J Med Plants Res 2009; 3(10): 799-808

17. Hanafi N, Mansour S. Antitumor Efficacy of salenostemma argel and/or y-irradiation against Ehrlich carcinoma. J Biol Sci 2010; 10(6): 468-79. https://doi.org/10.3923/jbs.2010.468.479

18. Aboul-Enein AM et al. Traditional medicinal plants research in Egypt: studies of antioxidant and anticancer activities. J Med Plants Res 2012; 6(5): 689-703.

19. Plaza A et al., New antiproliferative 14, 15-secopregnane glycosides from Solenostemma argel. Tetrahedron 2005; 61(31): 7470-7480.https://doi.org/10.1016/j.tet.2005.05.048

20. Horborne J. Phytochemical Methods, A Guide to Modern Techniques of Plant Analysis $3^{\text {rd }}$ Eds. 1998, Chapman and Hall, London.

21. Liu J, Xiao Y, Allen C. Polymer-drug compatibility: a guide to the development of delivery systems for the anticancer agent, ellipticine. J Pharm Sci 2004; 93(1): 132-143. https://doi.org/10.1002/jps.10533

22. United States Pharmacopeia and National Formulary (USP 41-NF 36). Rockville, MD: United States Pharmacopeial Convention 2016; 277:674, 731.

23. Patel J, Patel N, Shah SH, Formulation and in-vitro evaluation of mesalamine matrix tablets using chitosan for colonic drug delivery. J Pharm Res 2009; 2(7):1319-1323. https://doi.org/10.25258/ijpcr.v9i1.8260

24. Gohel $\mathrm{M}$, et al. Preliminary investigations in matrix based tablet formulations of diclofenac sodium containing succinic acid treated guar gum. Bollettino Chimico Farmaceutico 1998; 137(6): 198-203 https://doi.org/10.1016/j.jsps.2011.02.001

25. Alderborn G, Tablet and compaction In: Aulton M. Pharmaceutics: The science of dosage form design, Churchill Livingstone 2002; Longman group, Edinburgh

26. Nur AO, et al., Influence of type and content of guar gum as a disintegrant and production technique on attributes of immediate release tablets. Am J Pharm Tech Res 2014; 4(5): 546-57.https://doi.org/doi:10.3390/pharmaceutics3030440

27. Maderuelo C, Zarzuelo A, Lanao JM. Critical factors in the release of drugs from sustained release hydrophilic matrices. J Cont Rel 2011; 154(1):2-19.

https://doi.org/10.1016/j.jconrel.2011.04.002 